\title{
Extend the Teaching Breadth and Depth of the Concept of Derivative with the Aid of Informatization Idea
}

\author{
Yan Linjing \\ Institute of basic \\ Beijing Polytechnic \\ Beijing, China \\ yljustb@126.com
}

\begin{abstract}
This paper analyses the characteristics of mathematics and the present situation of the informatization instructional design, according to the concept of derivatives, with the help of information technology and informationization, the teaching design is carried out. From the overall design of one body and two wings, to the process of implementation is guided, learned and realized, to the "full layout of the information grid", Comprehensively expound the teaching innovation and change brought by the informationization technology and the informationization thought, Effectively broadening the teaching breadth and depth of "derivative concept", All aspects improve the students' math quality. The concept of "derivative" is further promoted in the chapter and provides examples for efficient design of other concepts.
\end{abstract}

Keywords-the concept of derivative; informatization; the teaching design; Advanced mathematics

\section{INTRODUCTION}

In the "Internet plus" era, various professions are setting off the upsurge of information technology. Engineering technology is more intelligent and precise, Data prediction is more accurate and reliable, and Social services are more convenient and user-friendly. So what does the powerful "information" catalyst bring to education? Since 2001, the national primary and secondary school curriculum for information technology has been initiated, this "source power" has led the education industry through three stages. In the first stage, the information technology course is added; the second stage is to develop information teaching and management platform for the school; in the third stage, the front-line teachers begin to integrate the thoughts and techniques of informatization into the teaching design and teaching process. This is also the direct meaning of information service education.

II. THE PRESENT SITUATION OF THE APPLICATION OF INFORMATION TECHNOLOGY INTERNALIZATION IN HIGHER EDUCATION AND THE CHARACTERISTICS OF MATHEMATICS DISCIPLINES

At present, In many subjects of higher education, Information technology appears in the teaching process of applied subjects, for example, Using anatomy and VR technology to explain anatomy in the medical profession, In the field of auto repair, 3D animation can be used to decompose parts structure, and the simulation system can be used to troubleshoot and repair teaching, In biology courses, simulation systems can be used to simulate cell cultures, In the field of art, we can also apply VR technology to the teaching of garment tailoring, Achieve the unity of fantasy and reality, and so on. The powerful power of "acting on behalf of static, replacing plane with three-dimensional instead of reality" is setting off a new revolution in education and teaching.

Mathematics is a basic subject in the stage of higher education, it focuses on training students' mathematical quality and modeling thought. Let the students accept mathematics abstraction ability, mathematics language ability in the learning process, logical thinking ability, mathematics application consciousness of mathematics training and clear, accurate, concise, rigorous and orderly expression of thought training mode of thinking. Let students understand the thought and essence of mathematics coming from life. Because of its instrumental characteristics, more attention should be paid to training students' logical thinking in the course of teaching, and the process of knowledge emergence, development and application is followed. Therefore, the theory of teaching is strong, abstract and application is not distinctive features, the application of information technology in teaching is still in the stage of hardware application of information technology. But it is the soul of information technology that integrates it into teaching design. This paper discusses the information teaching design process of "the concept of derivative".

\section{THE TEACHING MATERIAL ANALYSIS BASED ON "INFORMATIZATION" THOUGHT}

\section{A. Teaching orientation of the concept of derivative}

The concept of derivative is the core of calculus.

Longitudinal analysis, the concept of derivative is the deepening of functional knowledge and the development of extreme knowledge. It is also the premise of learning integral calculus and the ideological basis of establishing differential equation mathematical model under quantitative analysis index, and has important function of taking the past and the future [3]. 
From horizontal analysis, the concept of derivative is in a special position. It is the foundation of derivative operation, and the thought tool of property deduction and application.

\section{B. Basic teaching requirements}

Let students start from the background of derivative concept and understand the essential meaning of derivative. They will use the definition to find the derivative of function at one point, understand the geometric meaning of derivative, and complete the basic knowledge target [2].

In the learning process, students need to understand the formation process of the concept of derivative, and master from concrete to abstract, special to the general method of thinking, improve the analogy and abstraction, connection and transformation ability of thinking, at the same time, students are required to have the basic ability of using the concept of derivative analysis and solve practical problems, the basic idea of the establishment of the mathematical model.

Through the study of the concept of derivative, the students can experience and identify the dialectical view of "limited and infinite unity of opposites", realize the rationality and preciseness of mathematics, and improve the quality goals of students [4].

\section{The change of emphasis in the teaching of the concept of derivative}

In the past few years, the concept of derivative has merely been the method of removing the fundamental derivation formula. In the course of teaching, more attention should be paid to the calculation ability of students, and the deduction and demonstration of theory, that is to say, the concept of derivative, mostly plays the role of doing the question. With the advent of the information era, mathematical software gradually in the process of teaching, and promote the effective use of the powerful function of the software, so that teachers and students can easily click into place, we quickly derivation operation, mathematical model. This is not so easy for teachers and students to be lazy, but it is the change of ideas. We begin to think that if the mathematical model can be constructed, the solution will have its own. This means that we can spend more time and energy on studying the essential meaning of derivative concept. We can observe and explore many examples and gradually grasp the idea of modeling. Compared with before, the emphasis of teaching has shifted from form to essence, from theory to application. Also more let the student understand and realize "the acquired knowledge is useful, all applications have the basis", carries on the seepage quality education comprehensively.

\section{TEACHING DESIGN THOUGHT AND IMPLEMENTATION PROCESS BASED ON INFORMATION TECHNOLOGY}
A. The teaching design follows "one body, two wings", taking into account the course before class - - during class - after class

The idea of teaching design is the soul of teaching design. In order to broaden the teaching scope and depth of the concept of derivative, it is not enough to only grasp the classroom teaching, because it needs a penetration process of mathematical thinking. Inspired by the idea of informatization, we have designed it from two dimensions. On the time axis (horizontal axis), by means of information technology to carry out pre class guidance thinking, class thinking, exploration, after-school research, promotion, and gradually enhance students' understanding of the concept of derivatives, broaden their thinking. In the ability axis (vertical axis), the same way of information technology, specific interpretation of the concept of derivative concepts and connotations, thinking training, and gradually improve the modeling ideas, and realize the ability to improve. As follows:

\section{1) Subject of interpretation}

The teaching of the concept of derivative focuses on the essential meaning of the concept of derivative, that is, instantaneous change rate of change quantity [1]. The limit idea of infinite approximation is the foundation of students' understanding.Highlight all author and affiliation lines. To this end, we design an interactive animation based on the speed measurement principle of the automobile on the expressway. Students can drag the car, observe the "average speed and instantaneous speed gradually close to the trend, understand the point speed is actually the instantaneous speed, and can accurately write expressions of instantaneous velocity limit, grasp the essence of the derivative concept is the average rate of change. So as to realize the natural presentation of teaching subject and the deep understanding of the concept of derivative.

\section{2) Enrich the two wings}

Students are always the main body in the course of teaching, and the dynamic of teaching subjects is the advantage of information assisted instruction. In order to stimulate students' interest and let students have learning motivation, pre class preview can be accomplished by means of information technology. We passed the "cloud class", "WeChat public platform" release preview work, requiring students to access to information, understand the way and method of vehicle speed measurement, and complete the study report, share on the communication platform. Here, we allow students to play freely and lay a solid foundation for the implementation of classroom teaching. Through the information technology, we can not only monitor in real time, but also evaluate the students effectively, so as to perfect the trend of "spreading the wings".

The lasting motivation of learning is the interest, and the final result of learning is the improvement of learning ability. The objects we face are energetic but vulnerable to outside interference and temptation. They do not have good selfcontrol ability, and the interest guidance is essential after class. In the "landing" of this wing, we carefully designed to expanding assignments, including economic models, weight 
loss model. We combine mathematical theory and mathematical application to build a stage of independent innovation for students. They form a team to meet the challenge, and comrades in arms try to find out how to set up a mathematical model. Together, they explore the solution of the model, and realize the breadth and application of the concept of derivative, and deeply feel the joy of cooperation. In resource support, we provide a powerful online modeling course of study and rich mathematical model of case base, not only broaden their horizons, and give full play to the students' autonomous learning ability, form a continuous trend. With the support of information technology, students' works can be shared and communicated, and tutors can guide online, thus effectively ensuring the learning effect.

\section{B. The teaching process is guided by "guidance" - "learning" - "perception" as the main line.}

In the main part of classroom teaching, we take the "generation" of the concept as the starting point of teaching, and solve the actual cases to achieve the application of the concept of derivative. In the course of teaching, the subjectivity of students is distinct, and the three layers of teaching effect are developed step by step [6].

In the teaching part of the core, with "animation" as the introduction, to stimulate students' interest in thinking; interactive animation research, operated by the students, guide the students to actively explore, and reveals the background of the formation of concepts; and design a game, let the student through the calculation and understanding of the "derivative geometric meaning" to complete the actual circular cutting table, which is vivid and profound. "Guidance, learning and sentiment" as the clue, not boring, effectively highlight the teaching focus, and explain the depth of the concept of derivative.

In the concept of application, under the background of sponge City, we designed a water storage and drainage system similar to the sponge principle, which was completed by the student team for practical cases. In the process of solving, we still take "guidance, learning and perception" as the main line. Using animation to simulate, guide students to do analysis, group cooperation and real-time guidance, help students open the modeling ideas; and with the help of software to solve the problem at the same time, profound understanding of the concept of deep meaning and broad sense. Achieve the breakthrough of teaching difficulties and the sublimation of teaching content.

\section{Teaching process "information network layout", to achieve supervision - Evaluation - to expand multi-dimensional breakthrough}

(1)"Cloud class", "WeChat public platform", "network learning platform" reasonable distribution before class, class and after class. Effectively promote learning, sharing and evaluation.

(2)The specific process network diagram is as follows:
See Figure 1 for details

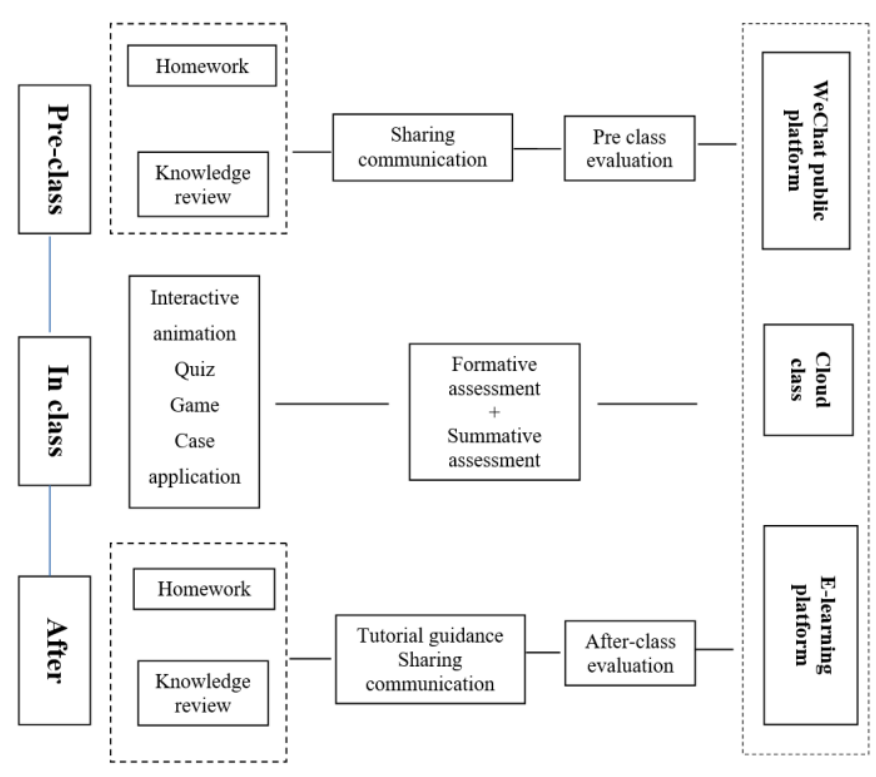

Fig. 1 Network diagram of teaching process

\section{THE TEACHING DESIGN BASED ON "INFORMATION" THOUGHT EXPANDS THE BREADTH AND DEPTH OF THE CONCEPT OF DERIVATIVE}

The concept of derivative is a mathematical concept class, and its content is abstract. From the past teaching experience, we have learned that students do not pay attention to the concept of the concept of the background, and the concept of understanding is not deep enough, but even do not know how to apply [5]. According to this study, we proceed from the actual application, and returned to the instructional design of practical application, following the discovery and the cognitive characteristics of students, and the use of information technology means to achieve the teaching emphases and difficulty of breakthrough. Let the students think actively, and understand the concept of derivative profound essence, and through the practice of expanding the depth; let the students learn the knowledge transfer through the case analysis, and ultimately achieve the organic combination of applied mathematics thought and mathematics, realize "the breadth and depth " of understanding and application of the concept of derivative.

To sum up, "informatization" thought has innovated the teaching meaning of derivative concept, and the information technology has assisted the teaching essence of derivative concept. Not only because of the application of information technology to enrich the teaching resources and the teaching process, to resolve the difficulty of teaching, but also because of the "information teaching design thought" into the originally dull theory into fresh tools, intensity. It makes the way of teaching become vigorous, deep and broad. 


\section{REFERENCES}

[1] Department of mathematics Tongji University. Higher mathematics. I [M]. Beijing: Higher Education Press.2014.(In Chinese)

[2] Li Yajie. Concise calculus [M]. Beijing: Higher Education Press,.2015. (In Chinese)

[3] Wang Zhigang, Yao Yan, Dong Shuyi. Research on the teaching of the concept of derivative [J]. Journal of Fuyang Normal College, 2015, 32 (4): 105-107. (In Chinese)
[4] Wang Yaping. Teaching strategy of derivative concept [J]. Journal of Tonghua Normal University, 2013, 34 (10): 81-82. (In Chinese)

[5] Wang Shuzhi. The training of derivative teaching to students' Quality Education [J]. Journal of Jilin Institute of education, 2009, 25 (9): 70-71. (In Chinese)

[6] Sun Yaxian. Stratified teaching of mathematics in Higher Vocational Colleges [J]. Journal of educational science of Hunan Normal University, 2008, 7 (2): 127-128. (In Chinese) 